\title{
Liquefaction analysis of abrasion protection structure in Padang
}

\author{
Abdul Hakam ${ }^{1, *}$, Bayu M Adji ${ }^{1}$, Junaidi $^{1}$, and Risayanti ${ }^{1}$ \\ ${ }^{1}$ Andalas University, Civil Engineering Department, 25163 Limau Manis - Padang, Indonesia \\ *Key-note speaker
}

\begin{abstract}
The liquefaction potential of a soil deposit is an important aspect to consider the stability of structure due to the earthquake. The liquefaction may also contribute to the safety of coastal constructions. The assessment of liquefaction potential can be started by having the physical properties of sandy soil that include grain size and density. Those parameters had known to give effects to the liquefaction resistance. Those physical properties of sand soil associated with liquefaction resistance must be tested in the laboratory. A case study of a real construction design in Padang, Indonesia is discussed here. The liquefaction potential was assessed using the Density-Grain size methods. The suggested solution to treat those problems is then provided. The compaction treatment to reach a certain relative density before the construction on site may avoid the liquefaction potential and save the coastal structure.
\end{abstract}

\section{Introduction}

One of the most dangerous occurrence causes of construction damage is liquefaction phenomenon in the saturated sand soil as happened to many constructions in Niigata (1964). That phenomenon becomes the starting point for the researcher to study intensively the liquefaction phenomena around the world. The method to estimate the liquefaction potential in the certain soil deposit the is suggested based on the liquefaction experience [1]. The liquefaction also happened during the Kobe earthquake in 1995 [2]. The areas were affected by the liquefaction mainly nearby reclaimed shoreline as shown in Fig. 1. The earthquake on 30 September 2009 in Padang has caused liquefaction in many areas, where are mostly in the riverbank and coastal areas [3]. Liquefaction occurs in the soil mass due to the increase of pore water while there is not enough time for that excessive pore water pressure to dissipate. The increase pore pressure can be the same as it overburdens pressure such that the effective stress in the soil mass become zore [4]. This condition then causes contact lost between soil grains. As explained by Al-Karni (2014) in his research [5], there is a change in the Stress-Strain behavior of sandy soil when the quick positive pore pressure builds up in the soil mass. In certain condition, the soil will lose most of its shear strength due to the loss of its effective stress and thus behaves as dense liquid. The changing behavior in that soil mass may effect on the stability of structure on it.

In the past, it has been summarized that for geologically new deposits of loose sands under the shallow groundwater table are very susceptible to liquefaction [6]. It has also been summarized the physical properties of soil that affect the potential of liquefaction such as histories, geological processes, soil types and sizes, density and stresses in the soil mass. Besides the earthquake properties such as applied peak acceleration and the time of occurrence of the earthquake, the soil parameters that are needed to be investigated related to the liquefaction potential are [7]\&[8]:

- The soil density,

- Stresses in the soil mass,

- Mean grain size of the soil,

- The history of consolidation,

- Pore pressure in soil mass,

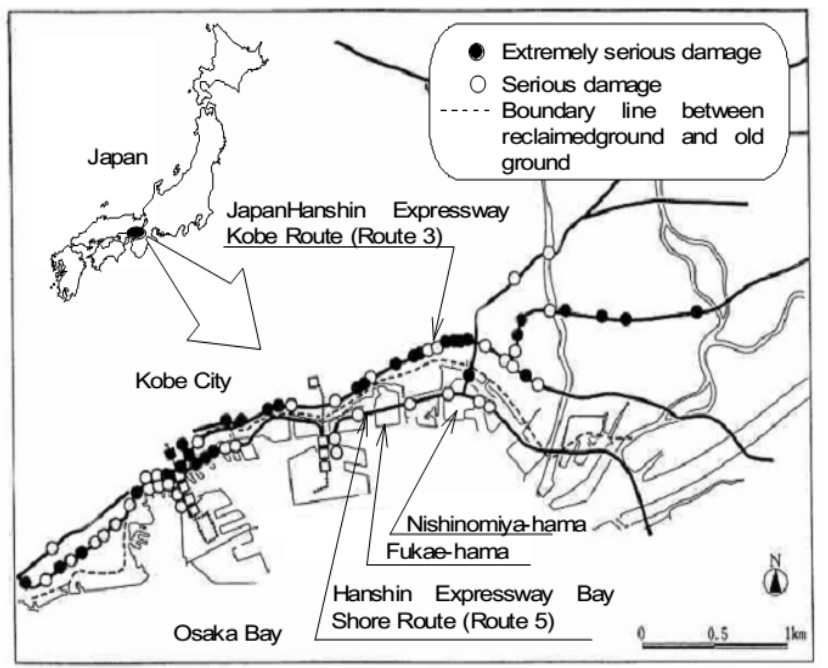

Fig. 1. Damage of piers in Kobe 1995 [2]

A recent laboratory test on sandy soil has shown that the pore pressure due to liquefaction can increase such that the stresses in the soil reached it failure envelope. These phenomena are illustrated by the Mohr-coulomb circles (Fig. 2).

* Corresponding author: abdulhakam2008@gmail.com, ahakam@eng.unand.ac.id 


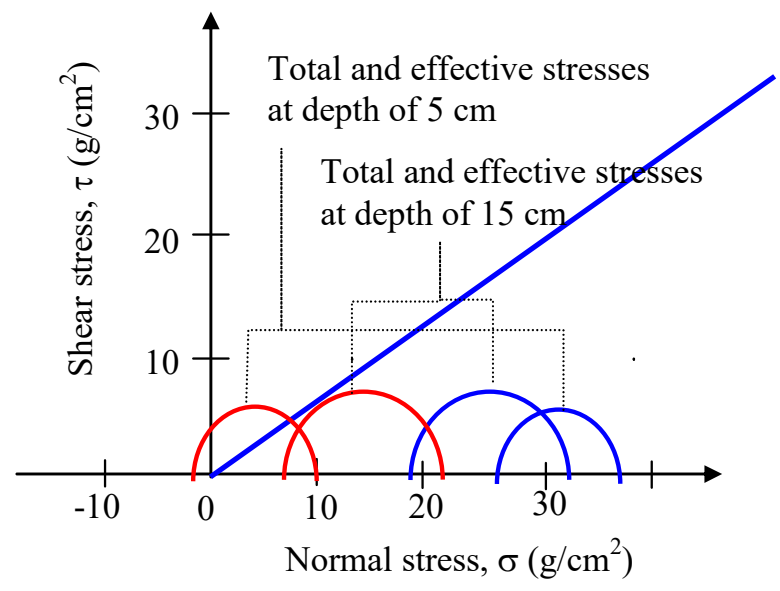

Fig. 2. Morh-coulomb circles in the test

\section{Liquefaction analysis}

The new liquefaction analysis method has been generated by the use of laboratory test results. The main results of those tests were the presented in the new chart as the tools to figure out the liquefaction potential (Fig. 3). The important parameters of the soil to be tested is the relative density Dr and grain size analysis. Both of those parameters of the soil are essentially used in practice.

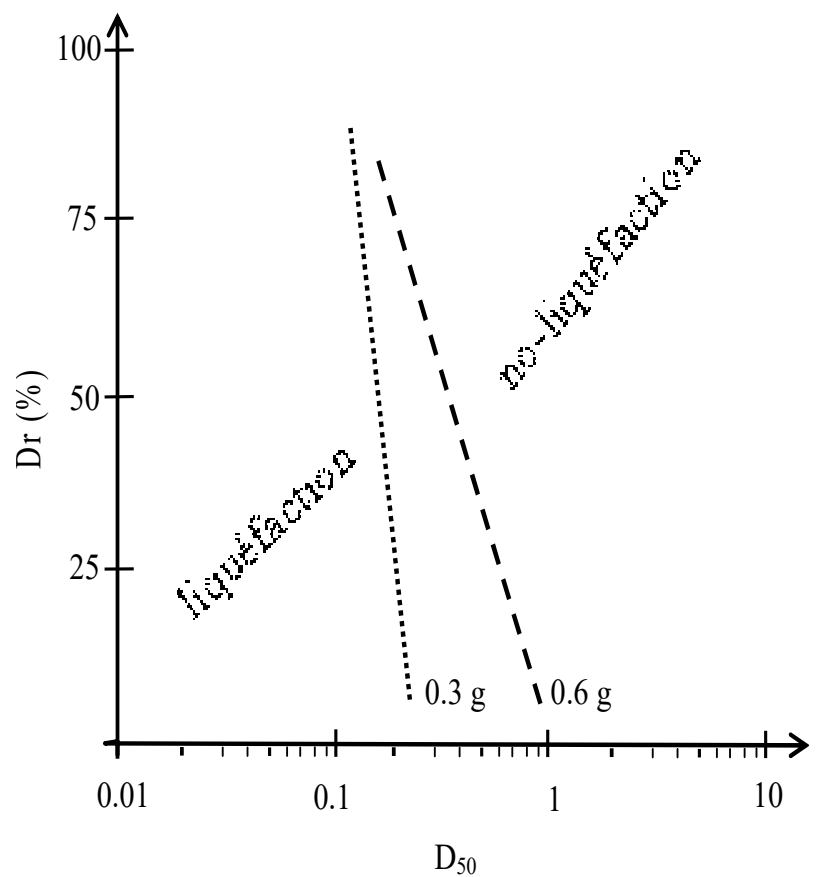

Fig. 3. Liquefaction potential chart (Hakam, 2016)

The grain sizes of the soil are tested using series sieve apparatus in the laboratory. The test results are then plotted in a soil distribution graph. Based on the Padang earthquake experience, the boundary of the liquefaction potential of soil grain distribution is concluded (Fig. 4).
This chart is then used as an important tool in liquefaction potential for any soil deposit.

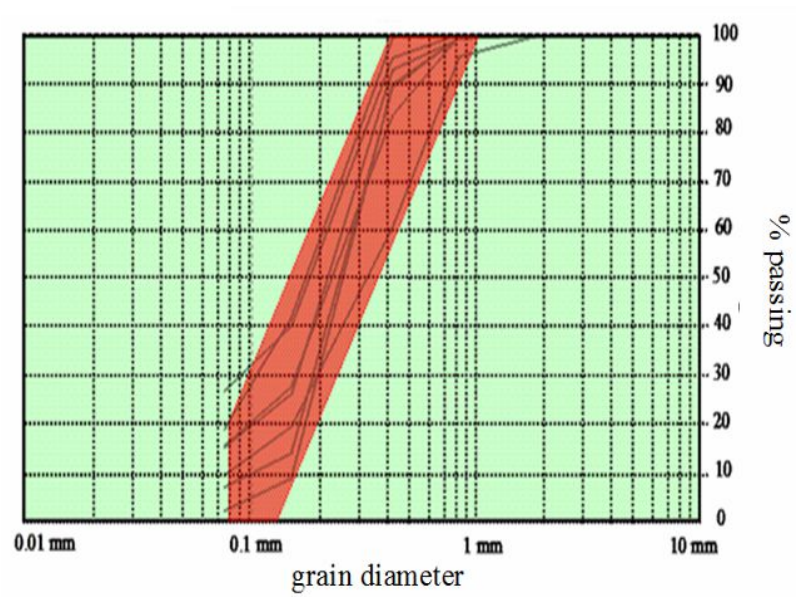

Fig. 4. Grain distribution chart [3]

The shadowed area in Fig. 4 is used as an initial control for soil grain distributions where the further liquefaction assessment using any methods is required. The grain distribution control is very cheap and can be understood easily since it involves the basic soil physical properties. Any soil investigations generally require the sieve analysis in order to accomplish soil classification. So, it needs no special additional budget in the soil investigation.

\section{The case study in Padang beach}

The study on shoreline changes due to the existence of abrasion conducted by field observation as well as literature review has been done. The past studies and investigations have concluded that the beaches in Padang need to be protected against abrasion.

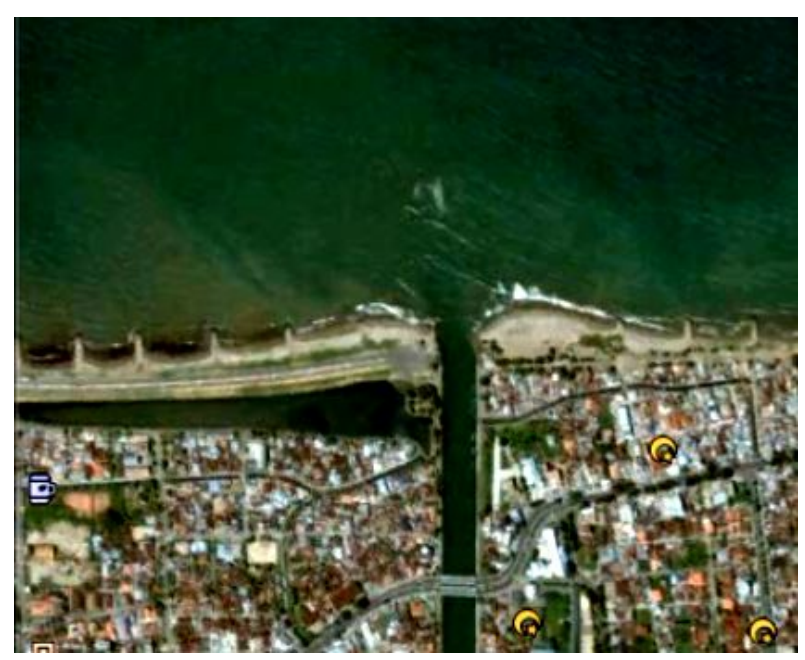

Fig. 5. Padang beach before groined in 2008

The local government has chosen the groin made of boulders to become the fittest structure to be constructed. The decision may come since there are many boulders 
near the Padang city. The map showed the Padang Beach before the construction (before 2008) as shown in Fig. 5. Then, it also showed the Padang beach after the bouldersgroin constructions in Fig. 6. A photograph of the typical groin constructed in Padang beach is shown in Fig. 7.

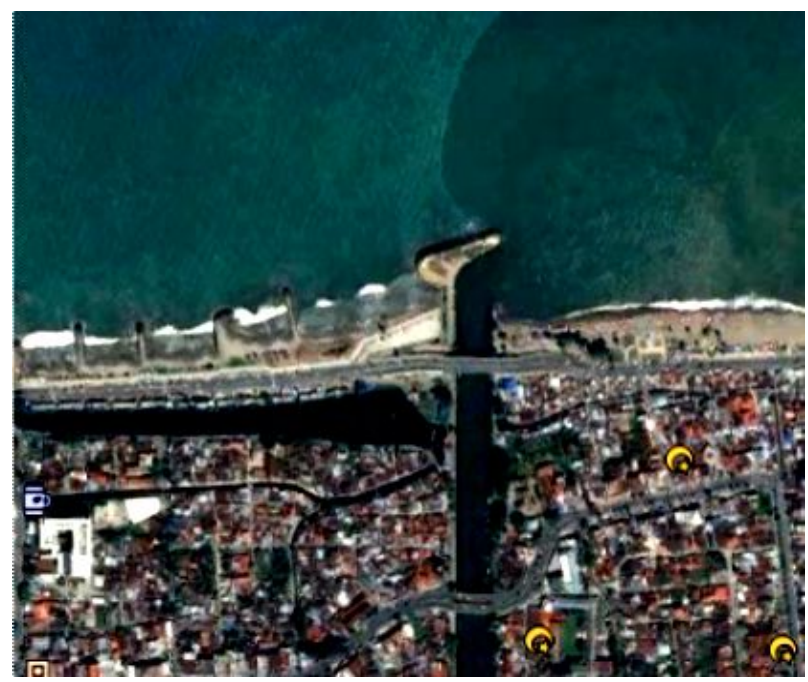

Fig. 6. Padang beach in 2018

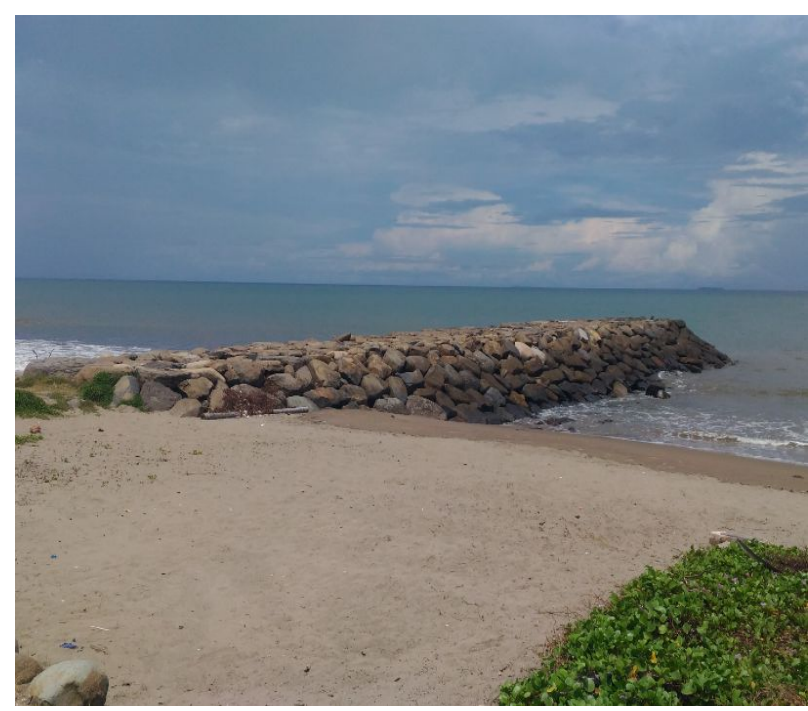

Fig. 7. Padang beach groin

The sieve analyses of Padang beach soils have been conducted in the past and recently. The sand soil samples are tested in 1983 and 2018. The result of the tests is plotted in the terms of percentage passing versus grain size distributions as shown in Fig. 8. It seems the grain distributions of Padang sand do not change much after 25 years. It indicates that the source of sediment and cycle of sediment transport at Padang beach do not change for years. It is can be seen clearly that the soil grain distribution graphs of the Padang beach sands are inside the shadowy liquefaction boundary. It indicates that in case of an earthquake the soil may liquefy and the groin structure stability could be affected.

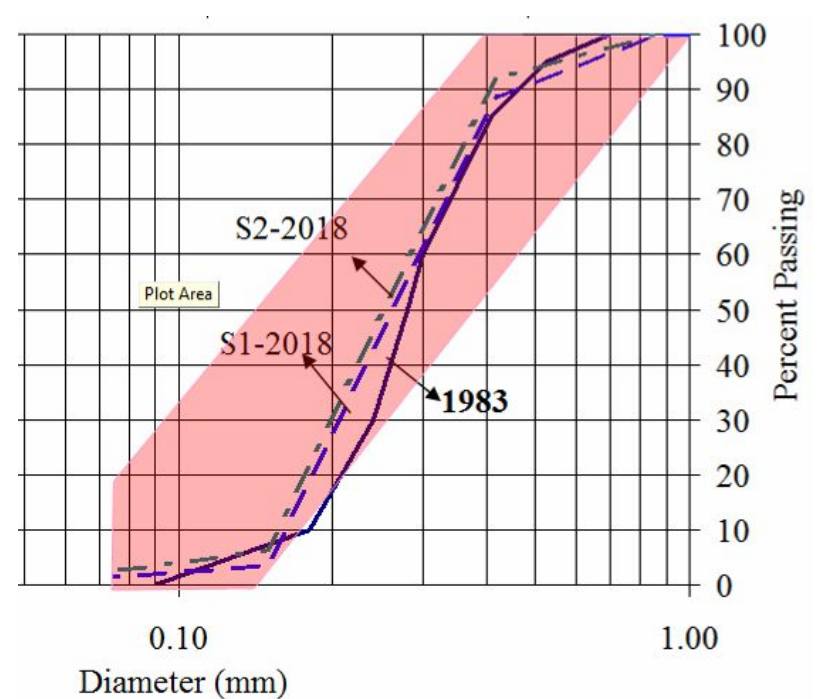

Fig. 8. The grain size of Padang beach sands

The mean grain diameters of the soils are $0.23 \mathrm{~mm}$, $0.25 \mathrm{~mm}$, and $0.28 \mathrm{~mm}$ for S2-18, S1-18, and S-83 samples respectively. These diameters are the plotted in the liquefaction potential chart as shown in Fig. 2. The surface ground acceleration maximum of Padang beach site is taken $0.3 \mathrm{~g}$ which is close to the Padang earthquake in 2009. The relative density of the soils is taken to be less $10 \%$ since they are just newly sediment soil originally transported by the sea waves. Those values are then plotted in the liquefaction potential chart and shown in Fig. 9.

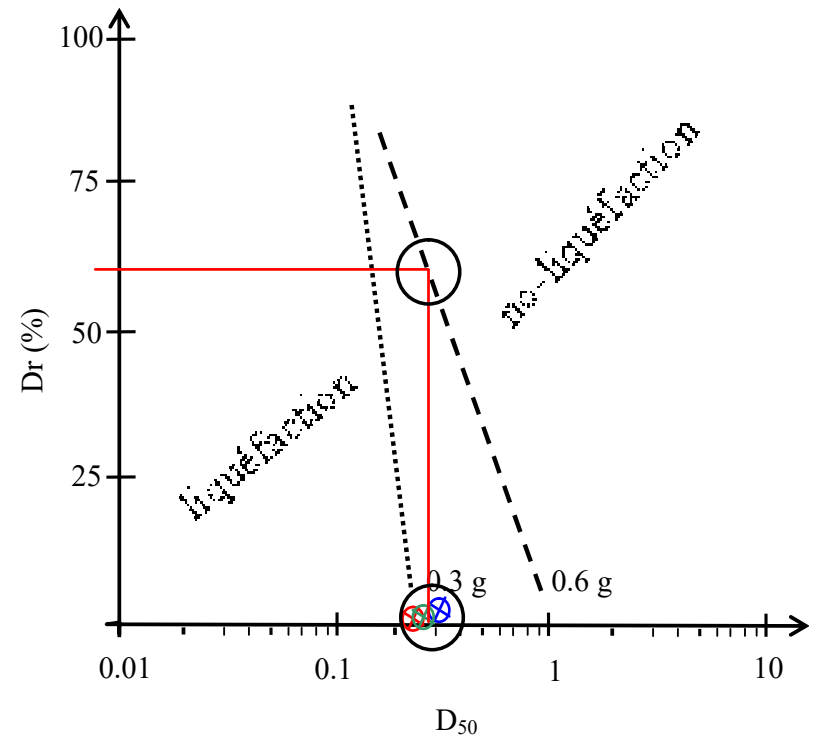

Fig. 9. Liquefaction potential of Padang beach sands

It can be seen that all of the sand is not in liquefaction potential area. It means that for the earthquake with the maximum acceleration less than $0.3 \mathrm{~g}$, the Padang beach sands will not liquefy and the groins in the Padang beach still in stable condition. However, for stronger earthquakes, the liquefaction may occur and affected the stability of the groins. In order to reach liquefaction 
resistant for a stronger earthquake, the base soil of groins needs to be compacted to reach a certain density. For illustration, in order to reach liquefaction resistant with the maximum acceleration $0.6 \mathrm{~g}$ the base soil of groins needs to be compacted to get density more than $60 \%$.

\section{Conclusions}

The liquefaction potential of a soil deposit is an important aspect to consider the stability of structure due to the earthquake. The liquefaction phenomena may occur in beach soils and affect the coastal constructions. The liquefaction potential can be assessed through the physical properties of soils in terms of grain size and density. Those properties can be obtained by testing soil samples in the laboratory.

A case study of liquefaction potential of beach sands in Padang Indonesia has been discussed here. The liquefaction potential was assessed using the DensityGrain size methods. The samples taken from the beach give the parameters which show no-liquefaction potential on them for earthquake less than $0.3 \mathrm{~g}$. But for an earthquake with the maximum acceleration more than $0.3 \mathrm{~g}$, the liquefaction potential is indicated. It is suggested the compaction treatment to reach a certain relative density before the construction on site to avoid the liquefaction potential and save the coastal structure for bigger earthquakes.

\section{References}

1. I. M., Idriss, and R. W., Boulanger, Soil liquefaction during earthquakes, Monograph MNO-12, Earthquake Engineering Research Institute, Oakland, CA, 261 pp., (2008)

2. T. Kokusho, Road Bridge Damage Due To Liquefaction During Level-2 Earthquake In Kobe, Journal of Japan Association for Earthquake Engineering, Vol.4, No.3 (Special Issue), 2004

3. A Hakam, Laboratory Liquefaction Test of Sand Based on Grain Size, and Relative Density, J. Eng. Technol. Sci., Vol. 48, No. 3, 2016, 334-344, (2016)

4. K. Terzaghi, Theoretical Soil Mechanics, Wiley, New York, (1943)

5. A.A. Al-Karni, Effect of Pore Water Pressure on Stress-Strain Characteristics of dense Sand, GeoShanghai International Conference, (2006)

6. S. L., Kramer, Geotechnical Earthquake Engineering, Prentice Hall, Englewood Cliffs, N.J., (1996)

7. R. W., Day, Geotechnical Earthquake Engineering Handbook, The McGraw-Hill Comp., (2002)

8. B. M., Das, Fundamental of Soil Dynamics, Elsevier Pub., New York, (1983) 